\title{
PA-051 MYCOBACTERIUM TUBERCULOSIS RESISTANCE TO ISONIAZID AND RIFAMPICIN IN A HIV-1 ENDEMIC POPULATION IN WESTERN KENYA IN 2014
}

Clement Likhovole, ${ }^{1}$ Collins Ouma, ${ }^{2}$ John Vulule, ${ }^{3}$ Susan Musau, ${ }^{3}$ Jeremiah Khayumbi, ${ }^{3}$ Albert Okumu, ${ }^{3}$ Wilfred Murithi ${ }^{3}$. 'Maseno University, Kenya; ${ }^{2}$ AFIDEP, Kenya; ${ }^{3}$ KEMRI, Kenya

\subsection{6/bmjgh-2016-000260.84}

Background The spread of mono-resistant and multi-drug resistant tuberculosis (MDR-TB) has been enhanced by delays in the identification of resistant strains. However, resistance gene patterns and the extent and distribution of mono-resistant $\mathrm{TB}$ and MDR-TB is unknown, particularly for western Kenya where Human Immunodeficiency Virus (HIV) is common. As such, the overall objective of the current study was to identify cases of mono-resistant TB and MDR-TB among enrolled patients in health facilities in western Kenya.

Methods Patients with a suspected TB history were referred by clinicians to the health facilities for TB and HIV diagnosis. HIV testing was done using the Unigold and Abbott Determine kits. Early morning sputum samples were collected and cultured on Mycobacteria growth indicator tubes (MGIT) and incubated at $37^{\circ} \mathrm{C}$. Drug susceptibility testing (DST) using the SIRE $®$ kit was done on $\mathrm{ZN}$ smear positive MGIT tubes and line probe assay (LPA) performed to identify specific mutations on the rpo B, kat $\mathrm{G}$ and inh A genes. Mutations on discordant samples were confirmed by the BigDye ${ }^{\circledR}$ Terminator v3.1 Cycle Sequencing Kit.

Results The proportion of MDR-TB, RIF mono-resistant (RMR) TB and INH mono-resistant TB as estimated by LPA and DST, was as follows: MDR-TB: 1.38\% / 1.26\%; RMR-TB: 1.2\% / 0.72\%; INH mono-resistant TB: $2.1 \%$ / 2.4\%, respectively. Our study showed that the H526Y rpo B and S315T1 kat $G$ mutations were common in HIV-positive patients $(8 \%$ and $18 \%$ respectively) and that the S3I5T1 and S531L was the most common mutation in MDR-TB strains in both HIV-positive and HIV-negative patients (5\% and $8 \%$ respectively). Binary logistic regression, indicated that RMR-TB significantly predicted HIV status $(\mathrm{p}=0.025)$.

Conclusions Our findings show that RIF mono-resistant TB predicts HIV infection. 